\title{
CHARACTERISTICS OF DISASTER-RELATED INFORMATION IN CASE OF THE HEAVY RAIN EVENT OF JULY 2018 -A CASE STUDY OF OKAYAMA, HIROSHIMA, AND EHIME PREFECTURES-
}

\author{
Mamoru YOSHIDA ${ }^{1}$, Daisuke KAMIYA ${ }^{2}$ and Maiku ABE ${ }^{3}$ \\ ${ }^{1}$ Member of JSCE, Associate Professor, Grad. School of Fisheries and Environmental Sciences, Nagasaki University \\ (Bunkyo-machi 1-14, Nagasaki 852-8521, Japan) \\ E-mail: yoshida-m@nagasaki-u.ac.jp (Corresponding Author) \\ ${ }^{2}$ Member of JSCE, Civil Engineering Program, University of the Ryukyus \\ (Senbaru 1, Nishihara, Okinawa 903-0213, Japan) \\ E-mail: d-kamiya@tec.u-ryukyu.ac.jp \\ ${ }^{3}$ Specially Appointed Assistant Professor, Education and Research Center for Mathematical and Data Science, \\ Hokkaido University (North12 West7, Kita-Ku, Sapporo 060-0812, Japan) \\ E-mail: mike_abe@cris.hokudai.ac.jp
}

\begin{abstract}
This study presents the characteristics of disaster-related meteorological information and evacuation protocol based on a case study of the heavy-rain event of July 2018. By clarifying their characteristics, this enables us to obtain policy implications for municipalities and residents to respond appropriately to imminent heavy-rain hazards. As a result, it was found that many municipalities did not issue the evacuation preparation protocol. In addition, the proportion of residents who received the evacuation protocol in the order of the evacuation preparation, the advisory, and the order, was less than $50 \%$ of the residents targeted by the order. Moreover, the national government recommends that municipalities should associate their issuance of evacuation protocol with the meteorological information; however, there were differences in the utilization of the meteorological information between the municipalities.
\end{abstract}

Key Words : disaster-related meteorological information, evacuation protocol, spatial-temporal database, the heavy-rain event of July 2018

\section{INTRODUCTION}

This study aims to clarify spatial and temporal characteristics of disaster-related meteorological information and evacuation protocol during the heavyrain event of July 2018. Meteorological information is provided by the Meteorological Agency and evacuation protocol is issued by municipalities. Both the meteorological information and the evacuation protocol are expected to help residents perceive imminent threats from hazards. In addition, meteorological information is considered to be one of the triggers for municipalities to issue evacuation protocol. By clarifying their characteristics and relationships, this enables us to obtain policy implications for municipalities and residents to respond appropriately to imminent hazards.

As a premise, the meteorological information is announced when certain physical conditions are satisfied; however, the evacuation protocol is issued only when the head of the municipality approves it. In other words, municipalities have discretion to issue it. In addition, the meteorological information, such as a heavy-rain warning, is announced to a secondary segmented region that principally responds to the municipality. On the other hand, the evacuation protocol can be issued to parts of a municipality. Due to these differences, residents' reactions to the meteorological information may be different from those of the evacuation protocol. In addition, the government recommends that municipalities should associate their issuance of evacuation protocol with the meteorological information. However, it is unclear how the municipalities refer to the meteorological information when they issue the evacuation protocol.

From this background, the authors created a spa- 
tial-temporal database of the meteorological information, which included a warning for heavy rainfall and landslide, and the evacuation protocol for all of the municipalities in the Okayama, Hiroshima, and Ehime prefectures. These prefectures were damaged more than the other prefectures during the heavy-rain event of July 2018. In general, heavy-rain events result in threats to the residents in limited areas, which can occur in one or more municipalities. However, this heavy-rain event damaged many municipalities beyond the boundary of prefectures. Although such events rarely occur, this event is suitable for this study.

\section{FRAMEWORK}

\section{(1) Heavy-rain meteorological information}

The heavy-rain warning system considers two types of risks: an inundation risk and a landslide risk. A heavy-rain warning (inundation) is announced on the basis of the surface water index (i.e., the amount of rain remaining accumulating on the surface of the ground) and a heavy-rain warning (landslide) is announced on the basis of the soil water index (i.e., the amount of rain soaking and accumulating in the soil) with a unit of a secondary segmented region that principally responds to the municipality. After a heavyrain warning (landslide), the Meteorological Agency and the affected prefecture collaboratively announce the landslide alert information in situations where life-threatening landslides can occur. In addition, the Meteorological Agency has operated the landslide alert judgement mesh information, currently called landslide risk mapping, since June 2013. The Meteorological Agency treats them as reference information to help municipalities issue the evacuation protocol $^{1)}$.

The emergency warning system ${ }^{2}$, including the heavy-rain emergency warning, was launched in August 2013. Emergency warnings are intended for extraordinary phenomena expected to be of a scale that will far exceed the warning criteria. It is required that residents should not let down their guard even if no emergency warning is currently in effect in the area $^{3)}$. It is important to take actions early wherever possible with reference to relevant weather bulletins, advisories, and warnings, which are updated in response to the latest phenomenon observations or predictions ${ }^{3)}$.

The heavy-rain emergency warning is announced in situations where heavy rainfall - with a level of intensity observed only once every few decades - is predicted in relation with a typhoon or other events. This emergency warning system announced a heavyrain emergency warning for municipalities in 11 prefectures, which was the greatest number of prefec- tures since this operation started. The heavy-rain emergency warning system also considers two types of risks: an inundation risk and a landslide risk. The criteria and indices of the heavy-rain emergency warning are different from those of the heavy-rain warning ${ }^{4)}$, but in general, heavy-rain warning (inundation or landslide) is announced after the heavy-rain warning (inundation or landslide). In addition, as for the landslide risk, the heavy-rain emergency warning (landslide) is supposed to be announced after the landslide alert information. The physical conditions differ between the heavy-rain warning, the heavyrain emergency warning, and the landslide alert information, but the order of their announcement is interrelated.

The Meteorological Agency also announces the recorded short-time heavy rain information, the flood forecast for designated rivers, a flood advisory/warning, and other information related to the issuance of evacuation protocol for floods. To assess areas damaged by floods, it is important to analyze this information. However, for the heavy-rain event of July 2018, most municipalities suffered from a landslide risk, but not a flood risk. Therefore, this study deals with only heavy-rain warnings, heavy-rain emergency warnings, and landslide alert information. These are pertinent to the issuance of evacuation protocol especially for landslide risks. Analysis specific to the flood-damaged areas is beyond the scope of this study.

\section{(2) Evacuation protocol}

To promote residents' evacuation in situations where their lives and properties suffer from hazardous threats, municipalities can issue evacuation protocol, such as Hinan Junbi /Koureisha tou Hinan Kaishi (evacuation preparation/start the evacuation of elderly people and others), Hinan Kankoku (evacuation advisory), and Hinan Shiji(Kinkyu) (evacuation order). The evacuation preparation has been in operation since 2005, and the preparation and the order were renamed in response to typhoon No. 10 in August 2016 ${ }^{5}$.

The national government recommends that municipalities should set multiple conditions, such as the meteorological information, water levels, precursors, and the actual damage, in order to issue the evacuation protocol. The guideline ${ }^{6)}$ recommends that for the conditions of the landslide risk, the heavy-rain warning (landslide) is treated as an information source for their decision making to issue the evacuation preparation. Similarly, the landslide alert information is an information source for the evacuation advisory. In addition, a heavy-rain emergency warning (landslide) is treated as an information source for reviewing the targets of the evacuation advisory and 
order. Municipalities should make use of the meteorological information to issue the evacuation protocol effectively because it is direct information that reflects on the objective threats of the hazards. This study investigates the characteristics of the issuances of the evacuation protocol and their correspondence with the meteorological information.

Note that the above relationship between the evacuation protocol and the meteorological information is merely a guideline. It takes time for the practitioners in municipalities to reflect it to their actual operations of the issuances ${ }^{7}$. There are some municipalities that provide the public with a manual to issue the evacuation protocol and to provide the issuance conditions according to the guideline; however, a few municipalities do not open their manual. In addition, some municipalities are supposed to issue the evacuation protocol based on a comprehensive decision, even when the preset conditions are not satisfied. The evacuation protocol is expected to reflect municipality-specific conditions, that is, geographic characteristics; thus, municipalities must have a certain discretion when making decisions regarding the issuance. On the other hand, if municipalities made an ad hoc decision on the issuances and used the meteorological information differently, they would lose trust in the evacuation protocol.

From this point of view, this paper describes the differences between the municipalities in terms of their operation of issuing the evacuation protocol and their use of meteorological information.

\section{(3) Spatial-temporal database of the disaster-re- lated meteorological information and evacua- tion protocol}

The authors created a spatial-temporal database for meteorological information, which included heavyrain warnings; heavy-rain emergency warnings; landslide alert information; and the evacuation protocol that consisted of the evacuation preparation, the evacuation advisory, and the evacuation order. The data was obtained from the Meteorological Agency website $^{8)}$ along with the emergency alert e-mails that were sent to the public by the municipalities in the Okayama, Hiroshima, and Ehime prefectures during the heavy-rain event.

This study estimated the numbers of residents targeted by the meteorological information and the evacuation protocol with the 2015 census $^{9)}$ data. The estimated numbers were used in the analysis to maintain the consistency of the data sources. Therefore, the numbers of the residents targeted by the evacuation protocol in the analysis were different from those added when they issued it. In regard to the concrete estimation method, the meteorological information was mostly announced to a municipality unit; thus, the number of residents that were targeted by the meteorological information used the census data directly. On the other hand, as previously described, the municipalities can issue the evacuation protocol to specific areas in their own municipalities, but they differ in their area-based segmentation. In other words, some municipalities issue it to only landslideprone areas, or some district units in their municipality. Therefore, the authors estimated the numbers of targeted residents with the evacuation protocol by using an area-based weighting interpolation technique with the census data. The geographic information system (GIS) data of the segmented area targeted by the evacuation protocol can be downloaded ${ }^{10)}$.

\section{CHARACTERISTICS OF THE HEAVY- RAIN WARNING AND THE LAND- SLIDE ALERT INFORMATION}

\section{(1) Number of targets of heavy-rain warning and landslide alert information}

The recipients of the meteorological information include the municipalities and the residents; hence, the authors analyzed the characteristics from both perspectives. Note that the following statements are based only on an analysis from the perspective of the municipalities because they are similar and they overlap. The characteristics from the perspective of the residents strongly reflect those from the viewpoint of the highly populated municipalities.

First, it summarizes the entire timely process of the heavy rain warning and the landslide alert information. Figure 1 represents the number of targets of the meteorological information in the Okayama, Hiroshima, and Ehime prefectures in a timely manner. Some municipalities were targeted by the heavy-rain advisory before midnight of July 5, 2018, and the main heavy-rain event started just before noon of July 5 . The municipalities that were targeted by the heavyrain emergency warning appeared on the evening of July 7 , and it seems that they were targeted for more than half-a-day. In addition, it shows that almost all the municipalities in the three prefectures were targeted by the meteorological heavy-rain warnings between noon on July 5 to midnight on July 9. This is because the total number of municipalities that were targeted by the heavy-rain advisory, warning, or emergency warning was almost similar. Furthermore, it shows that the number of municipalities targeted by the landslide alert information gradually increased from 6:00 p.m. on July 5, and most of the municipalities were targeted before midnight on July 7 . This is an overall summary of this event based on the announced meteorological information. The detailed characteristics for each prefecture are described later. 


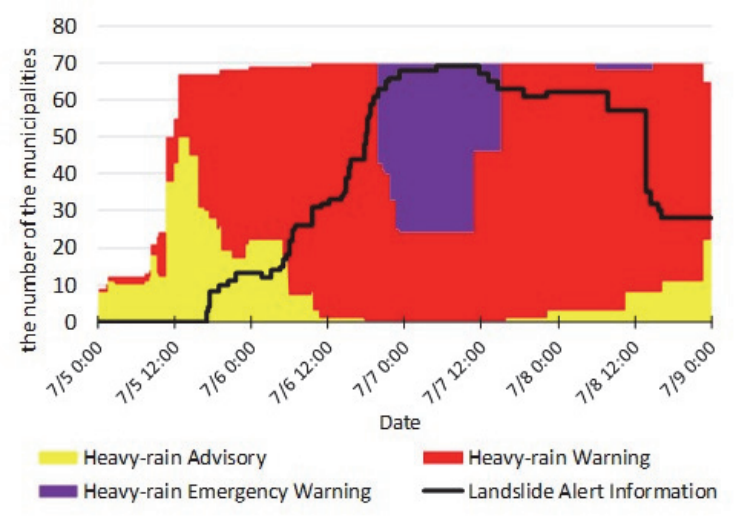

a) the number of municipalities

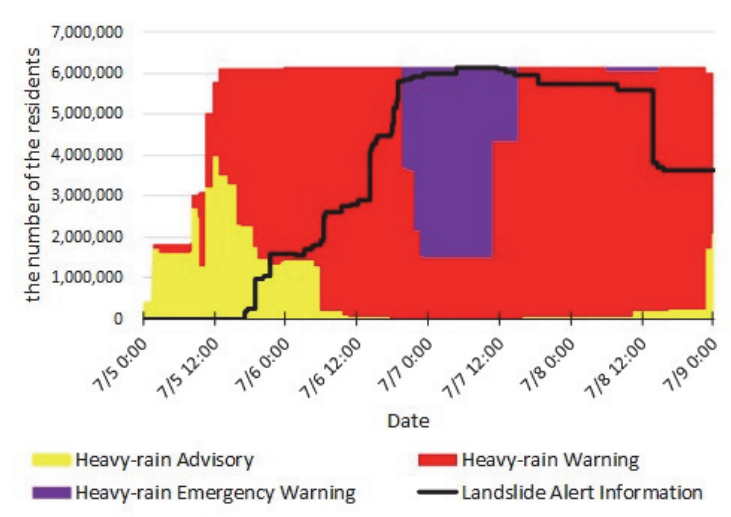

b) the number of residents

Fig. 1 Timely transfer of the number of targets of the heavyrain warning and the landslide alert information.

(2) Proportion of targets with the heavy-rain warning and the landslide alert information

Figure 2 represents the proportions of the targets of the heavy-rain warning and the landslide alert information in each prefecture. The proportion of the heavy rain warning (inundation) varies across the prefectures. The proportion of the municipalities that were targeted by the heavy-rain warning (inundation) was more than $90 \%$ in Ehime, but it was less than $50 \%$ in Okayama. On the other hand, almost all the municipalities in the three prefectures were targeted by the heavy-rain warning (landslide) and landslide alert information. In addition, the proportion of the municipalities that were targeted by the heavy-rain emergency warning (inundation) was more than $60 \%$ in Hiroshima, $20 \%$ in Okayama, and less than $10 \%$ in Ehime. On the other hand, the proportion of the municipalities that were targeted by the heavy-rain emergency warning (landslide) was approximately 90\% in Okayama and Hiroshima, but less than 10\% in Ehime.

Next, Figure 3 represents the proportions of the targets by the heavy-rain warning and the landslide alert information based on the order of the announcements. As a result, the proportion of the municipalities targeted by the heavy-rain emergency warning

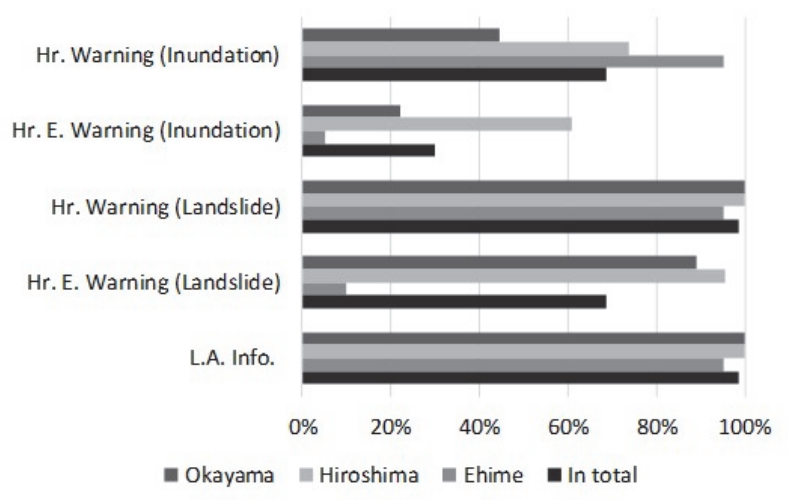

a) per municipality

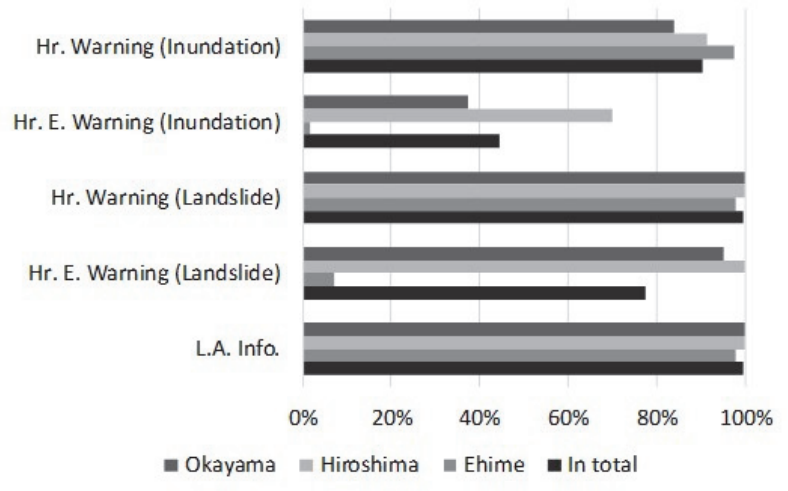

b) per resident

Fig. 2 Proportion of the targets of the heavy-rain warning and the landslide alert information.

(inundation) after the heavy-rain warning (inundation) differed between the prefectures. There were more than $70 \%$ municipalities in Hiroshima but less than $10 \%$ in Ehime. On the other hand, all of the municipalities in the three prefectures that were targeted by the heavy-rain warning (landslide) were targeted by the landslide alert information. Finally, the proportion of the municipalities that were targeted by the heavy-rain emergency warning (landslide) after the landslide alert information was more than $90 \%$ in $\mathrm{Hi}$ roshima, and approximately $10 \%$ in Ehime.

It can be observed that the municipalities differed in terms of the inundation risk, but those, particularly in Okayama and Hiroshima, were similar in regard to the landslide risk.

Next, we confirmed whether the municipalities could receive meteorological information based on the threat level. Figure 4 represents the proportions of the municipalities that were targeted by the heavyrain warning (inundation) before the heavy-rain emergency warning (inundation), the heavy-rain warning (landslide) was before the landslide alert information, and the landslide alert information was before the heavy-rain emergency warning (landslide).

The results show that almost half of the municipalities in Okayama were not targeted by the heavy-rain 


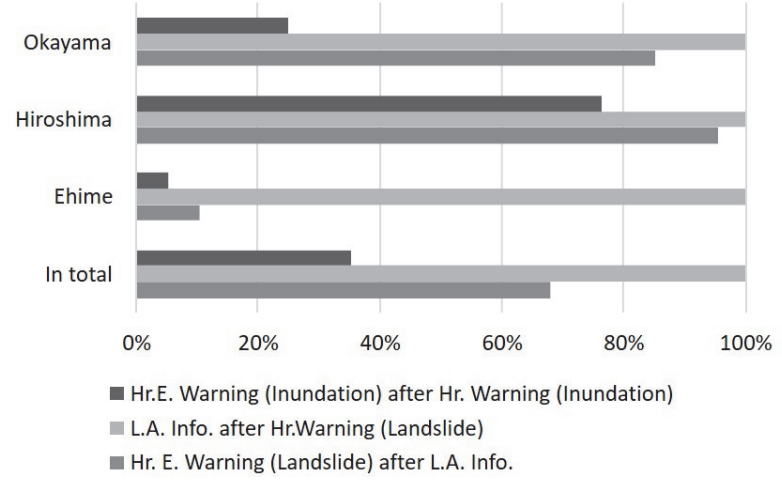

a) per municipality

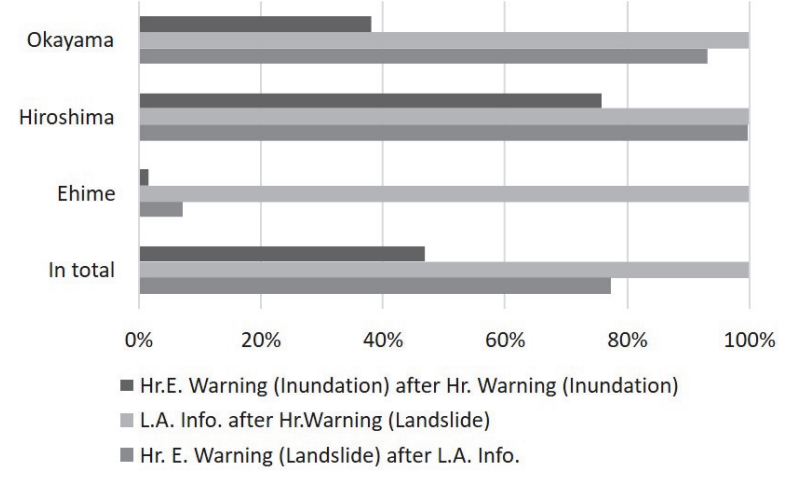

b) per resident

Fig. 3 Proportion of the targets of the heavy-rain warning and the landslide alert information based on the announcement order.

warning (inundation) before the heavy-rain emergency warning (inundation). On the other hand, almost all of the municipalities were targeted by the landslide alert information before the heavy-rain emergency warning, and all of the municipalities were targeted by the heavy-rain warning (landslide) before the landslide alert information. These characteristics were consistent with the preset conditions for their announcements.

There were cases where the municipalities were targeted by the heavy-rain emergency warning (inundation) without an explicit announcement of the heavy-rain warning (inundation). This happened in some municipalities, especially in Okayama during this event. In general, people suffering from the inundation risk are different from those that are suffering from the landslide risk. This implies that some people might suddenly notice that the inundation risk was coming since they received the heavy-rain emergency warning (inundation). Similarly, although this study did not include an analysis of the heavy-rain advisory, there were cases in which the heavy-rain warning was announced without the heavy-rain advisory. Note that there are cases where the meteorological information, especially for the inundation risk, is not always announced in order of the threat level.

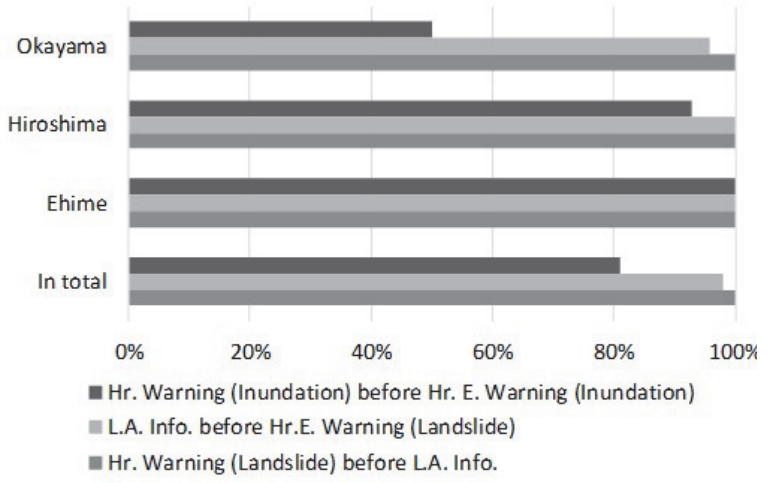

a) per municipality

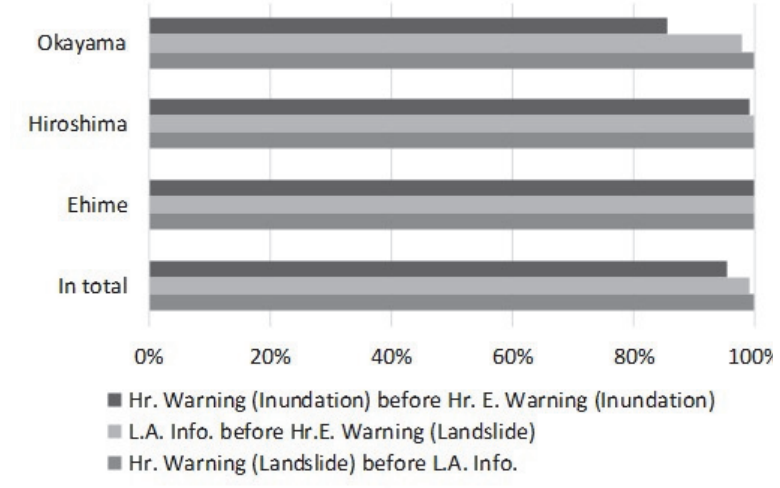

b) per resident

Fig. 4 Proportion of the targets of the heavy-rain warning and the landslide alert information based on the reverse order of the announcements.

\section{(3) Time period and time interval of the heavy- rain warning and the landslide alert infor- mation}

Figure 5 represents the accumulated number of residents that were targeted by the meteorological information announced from July 5 to July 8, 2018, over a three-hour time period. The analysis for the number of municipalities is similar; hence, it is omitted. In Okayama, heavy-rain warnings were announced from 3:00 p.m. to 9:00 p.m., and the heavyrain emergency warnings were announced from 6:00 p.m. until midnight. In Hiroshima, the heavy-rain warnings were mainly announced before or during the daytime, and the heavy-rain emergency warnings were intensively announced from 6:00 p.m. until midnight. In Ehime, on the other hand, the heavy-rain warnings were announced from night until dawn, and the heavy-rain emergency warnings were announced at dawn; however, two municipalities were targeted. In addition, the landslide alert information was announced from 9:00 a.m. until midnight in Okayama, from noon until 9:00 p.m. in Hiroshima, and from 3:00 a.m. to 9:00 a.m. in Ehime. As a result, the time periods when the municipalities received the meteorological information were not the same even though they were in the same prefecture. It is beyond the 


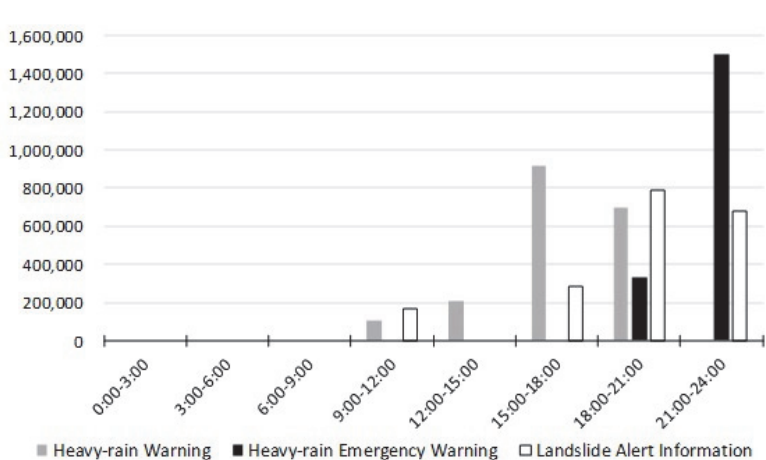

a) Okayama

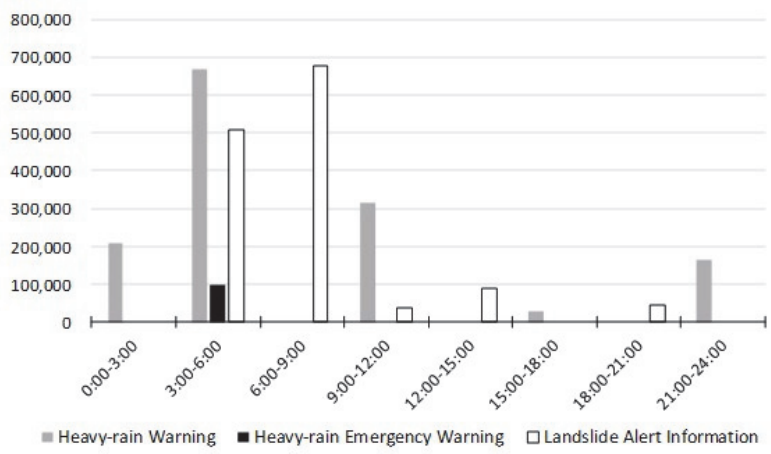

c) Ehime

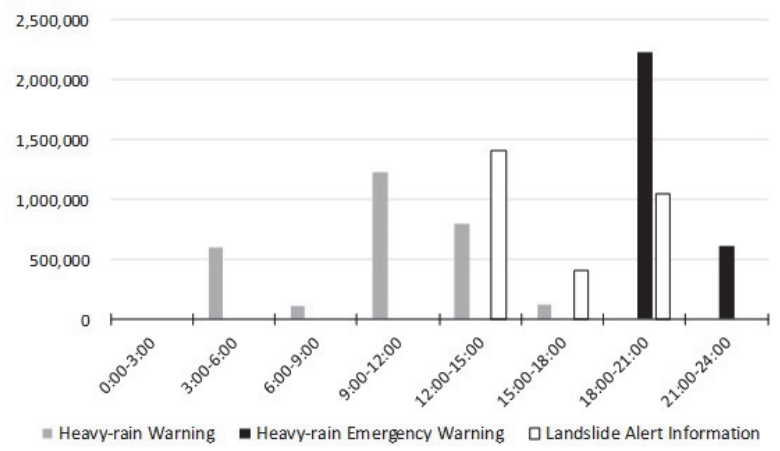

b) Hiroshima

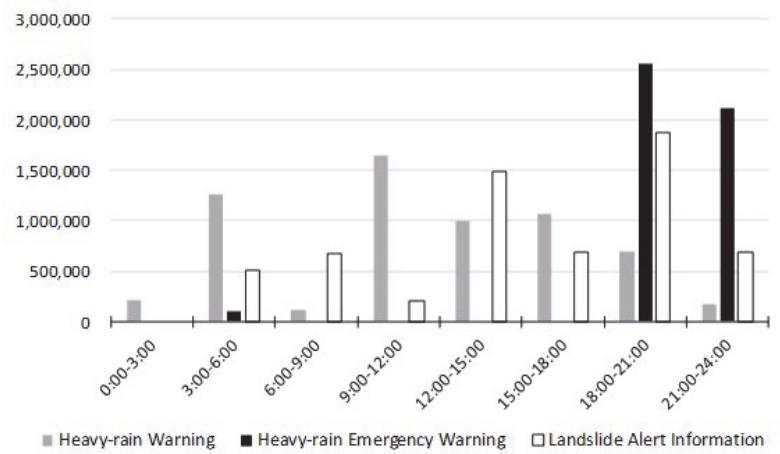

d) In total

Fig.5 The accumulated number of residents that were targeted by the heavy-rain warning and the landslide alert information over a three-hour time period.

scope of this study, but the time periods of the announcements might affect the municipalities and the residents. The municipalities and residents are required to plan a response to heavy-rain events while considering when the meteorological information is announced.

Next, Table 1 presents the summary statistics, which includes the mean values, standard deviations, maximum values, and minimum values for the time interval between the announcements of the meteorological information. Note that the heavy-rain warning and the heavy-rain emergency warning considers two types of risks: the inundation risk and the landslide risk, in order to clarify which risk is imminent.

The results show that the time interval between the heavy-rain warning (inundation) and the heavy-rain emergency warning (inundation) was more than one day in Okayama and more than two days in Ehime, but it was less than half-a-day in Hiroshima. In particular, Kumano Town in Hiroshima recorded the minimum value of the time interval, which was 39 min. The speed of the approaching inundation risk was very different between the municipalities; however, the time interval could be less than $1 \mathrm{~h}$. Second, in regard to the information for the landslide risk, the mean value of the time interval between the heavyrain warning (landslide) and the landslide alert infor- mation for all the municipalities in the three prefectures was more than 16 , but the shortest time interval was $34 \mathrm{~min}$ in Matsuyama City, Ehime, and $62 \mathrm{~min}$ in Kasaoka City, Okayama. Further, the mean value of the time interval between the landslide alert information and the heavy-rain emergency warning (landslide) in total was approximately $12 \mathrm{~h}$, but the shortest time interval was $1 \mathrm{~h}$ in Sera Town, Hiroshima.

The differences in the time intervals are attributed to the rain or the preset physical conditions for the announcements. The time intervals between the heavy-rain warning (inundation) and the heavy-rain emergency warning (inundation), the heavy-rain warning (landslide) and the landslide alert information, and the landslide alert information and the heavy-rain emergency warning (landslide) can be less than $1 \mathrm{~h}$. Municipalities and residents should take this fact into consideration in planning a response to heavy-rain events.

\section{CHARACTERISTICS OF THE EVACUA- TION PROTOCOL}
(1) Timely transfer of the number of residents tar- geted by the evacuation protocol

Figure 6 represents a timely transfer of the number 
Table 1 Time interval between the heavy-rain meteorological information and the landslide alert information.

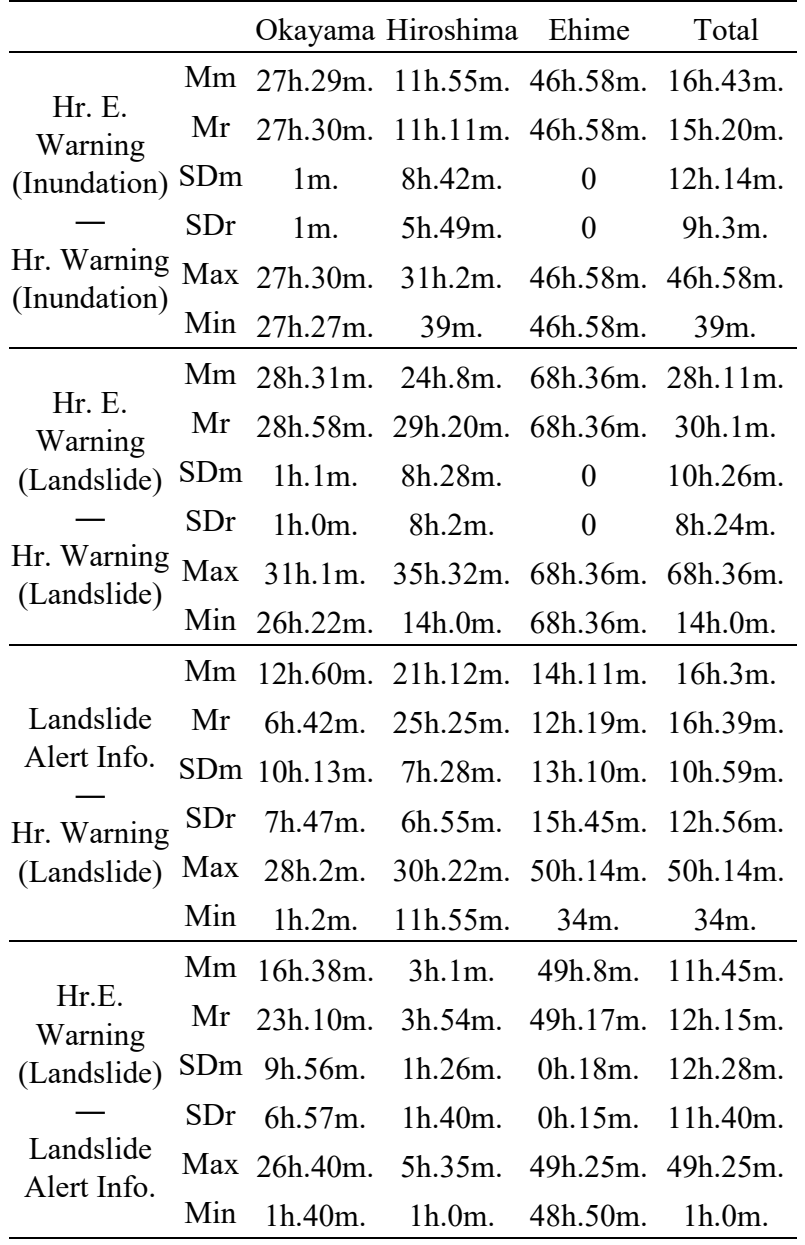

Abbreviations:

Hr., Heavy-rain; E., Emergency; Info., Information;

Mm, mean per municipality;

SDm, standard deviation per municipality;

$\mathrm{Mr}$, mean per resident;

SDr, standard deviation per municipality;

Max, maximum; Min, minimum;

h., hour(s); m., minute(s)

of residents that were targeted by the evacuation protocol from July 5 to July 10,2018 . It shows the overall trend of the targets of the evacuation protocol. Evacuation preparations were issued in the evening of July 5, and evacuation advisories were gradually issued during the afternoon and evening of July 6 . Subsequently, the evacuation orders were issued late in the evening on July 6 . After that, the evacuation orders were gradually released; however, many residents were targeted until the morning of July 9. The following describes the proportion of the targets, the time period, and the time interval for the evacuation protocol from the residents' point of view.

\section{(2) Proportion of the residents targeted by the} evacuation protocol

In general, there are cases where the evacuation

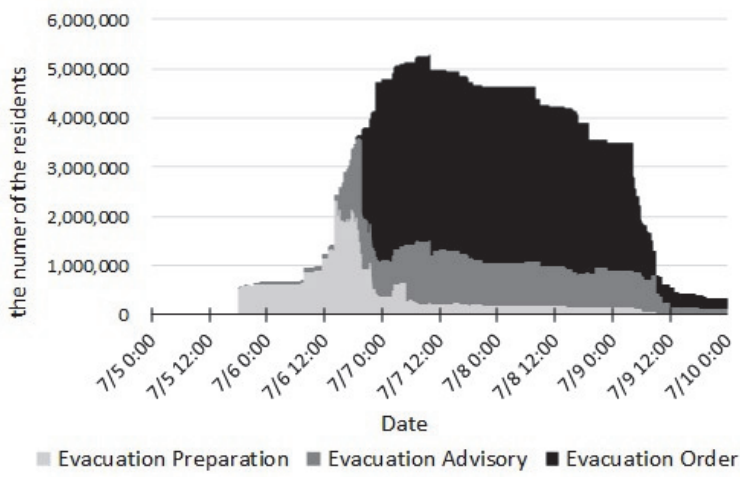

Fig. 6 Timely transfer of the number of residents targeted by the evacuation protocol.

preparation is issued either after the evacuation advisory or the evacuation order, or the evacuation advisory is issued after the evacuation order during the release process. To focus on the process of approaching the heavy-rain threats, the following analysis excluded the evacuation preparations and advisories in the above processes.

Figure 7 represents the proportions of residents that were targeted by the evacuation protocol during the period. The results show that the proportion of residents that were targeted by the evacuation preparation was approximately $40 \%$ in Okayama and Ehime, but more than $80 \%$ of the residents were targeted in Hiroshima. The proportion of residents that were targeted by the evacuation advisory was less than $50 \%$ in Okayama and Ehime, but more than $60 \%$ of the residents were targeted in Hiroshima. Finally, the proportion of the residents that were targeted by the evacuation order was more than $90 \%$ in Hiroshima, but approximately $50 \%$ in Okayama and less than $10 \%$ in Ehime. The differences in proportion were very large.

Next, Figure 8 represents the proportions of the residents that were targeted by the evacuation protocol based on the temporal order of the issuances. In general, the evacuation protocol is supposed to be issued in the order of evacuation preparation, evacuation advisory, and the evacuation order. From this, the issuance process partially reflects how the municipalities recognize a process of approaching heavyrain threats. The figure shows that the proportion of the residents that were targeted by the evacuation advisory after the evacuation preparation was approximately $70 \%$ in all the prefectures, but those that were targeted by the evacuation order after the evacuation advisory differed in each of the prefectures. This was more than $90 \%$ in Hiroshima, but no more than $40 \%$ in Okayama and $10 \%$ in Ehime. In addition, the proportions of the evacuation order after the evacuation preparation had a similar result. This implies that 


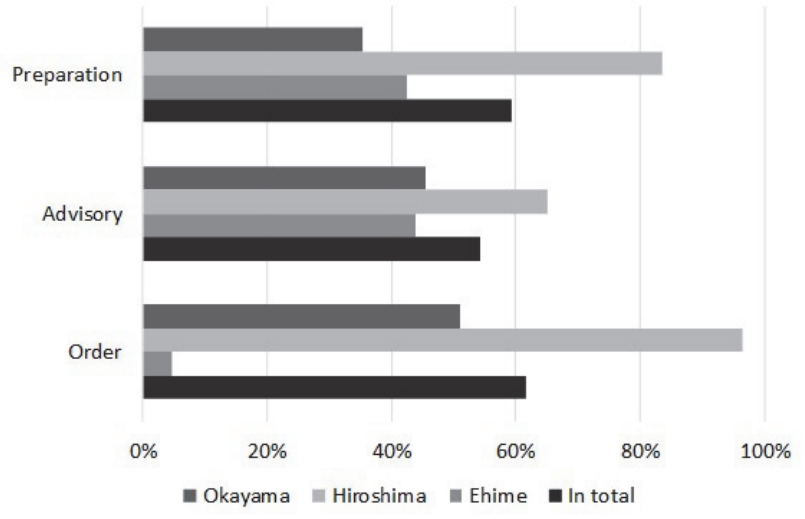

Fig. 7 Proportion of the residents targeted by the evacuation protocol.

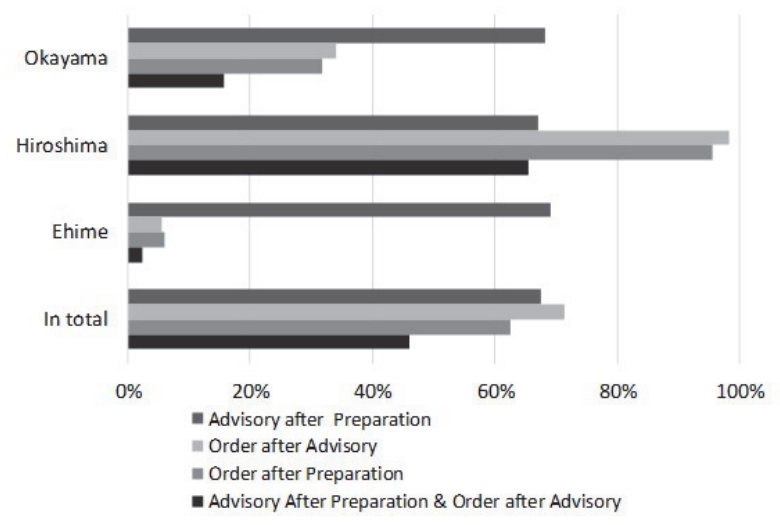

Fig. 8 Proportion of the residents targeted by the evacuation protocol based on the temporal order.

more municipalities in Hiroshima issued the evacuation protocol in stages, as expected.

Let us confirm whether the municipalities can issue the evacuation protocol in the order of evacuation preparation, evacuation advisory, and evacuation order. Figure 9 represents the proportions of the residents that were targeted by the evacuation protocol based on the reverse temporal order: (1) the evacuation advisory before the order, (2) the preparation before the order, (3) the preparation before the advisory, and (4) the advisory before the order, and the preparation before the advisory. If all the municipalities could issue the evacuation protocol in the expected stages, all the proportions resulted in 100\%.

The results indicate that the municipalities in Hiroshima were relatively successful in the operation of the issuances. The proportion of residents targeted by the evacuation preparation before the evacuation advisory was more than $80 \%$, which was similar to the evacuation preparation before the evacuation order. These results imply that many municipalities in Hiroshima could make use of the evacuation preparation protocol effectively. However, the former was less than $30 \%$ and the latter was slightly over $50 \%$ in Okayama, and the former was approximately $50 \%$,

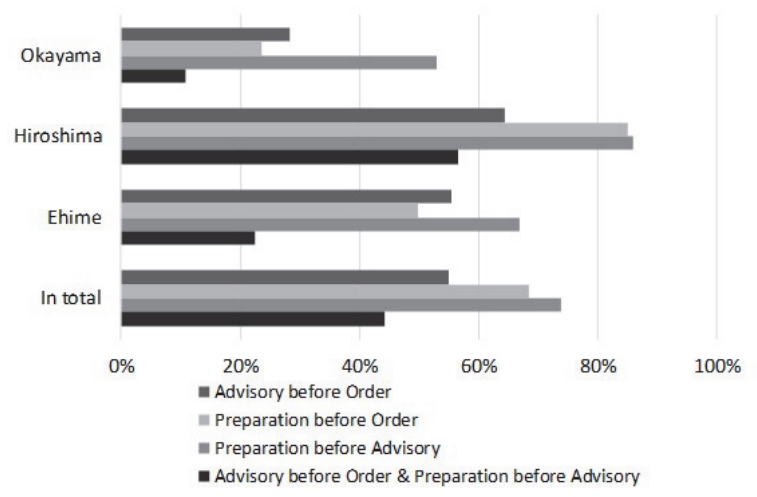

Fig. 9 Proportion of the residents targeted by the evacuation protocol based on the reverse temporal order.

and the latter was less than $70 \%$ in Ehime. These proportions implies that many municipalities in the two prefectures did not issue an evacuation preparation; nevertheless, they should have issued it. In addition, among the residents that were targeted by the evacuation order, the proportion of the residents targeted by the evacuation preparation, evacuation advisory, and evacuation order, in that order, was no more than $60 \%$, even in Hiroshima. Even worse, it was approximately $10 \%$ in Okayama and approximately $40 \%$ in Ehime. Consequently, it was less than $50 \%$ for all the municipalities in the prefectures.

\section{(3) Time period and time interval of the evacua- tion protocol}

Figure 10 represents the accumulated number of residents that were targeted by the evacuation protocol between July 5 to July 10 over a three-hour time period. Evacuation protocols were issued during different time periods in each prefecture. Evacuation advisories were issued from 3:00 p.m. until midnight in Okayama, from noon until midnight in Hiroshima, and from 6:00 a.m. to 9 a.m. in Ehime. Finally, evacuation orders were issued from 9:00 p.m. until midnight in Okayama, and from 6:00 p.m. until midnight in Hiroshima.

The guideline recommends that the evacuation protocol should be issued without hesitation even at night. For this heavy-rain event, many municipalities issued an evacuation order after the sun went down as recommended. As discussed later, most of the issuances for the evacuation order were triggered by the heavy-rain emergency warning just before midnight. This seemed to be one of the reasons why there were a few issuances from midnight until dawn. This event was not suitable to verify that the municipalities issued evacuation protocol with no hesitation from midnight until dawn. However, it is important to note that municipalities and residents should presume threats of heavy rainfall are possible during this time period. 


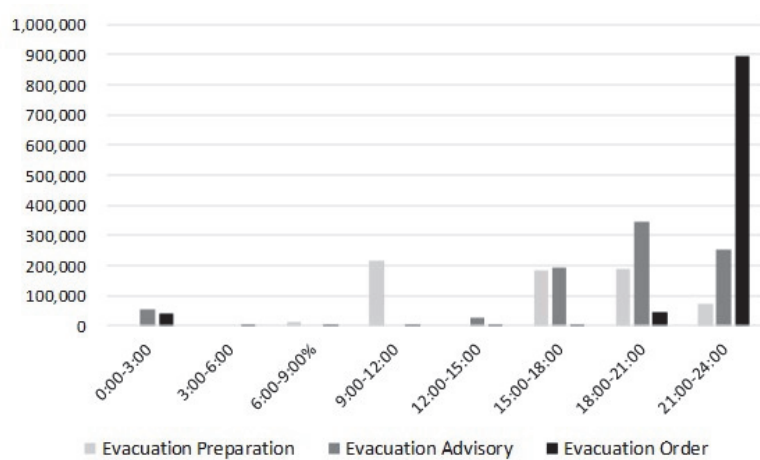

a) Okayama

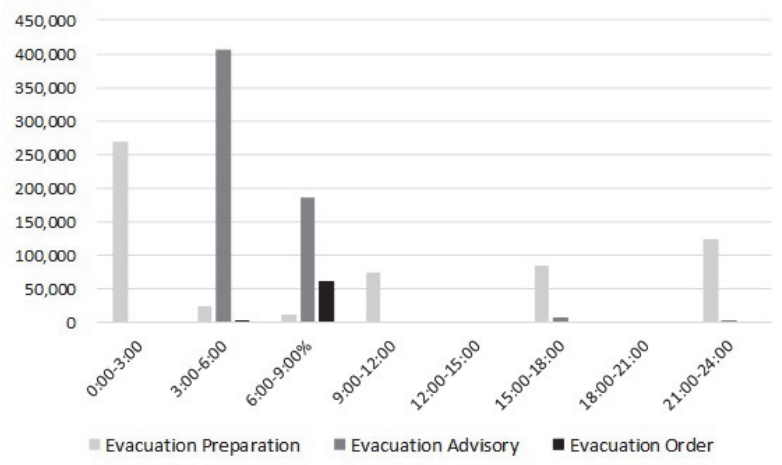

c) Ehime

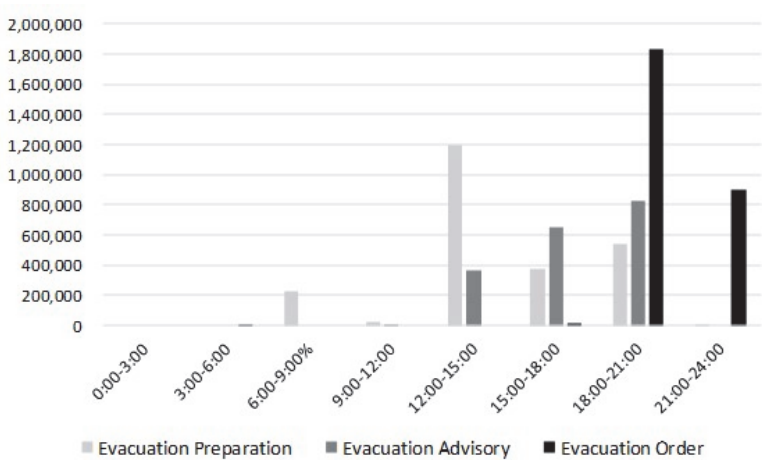

b) Hiroshima

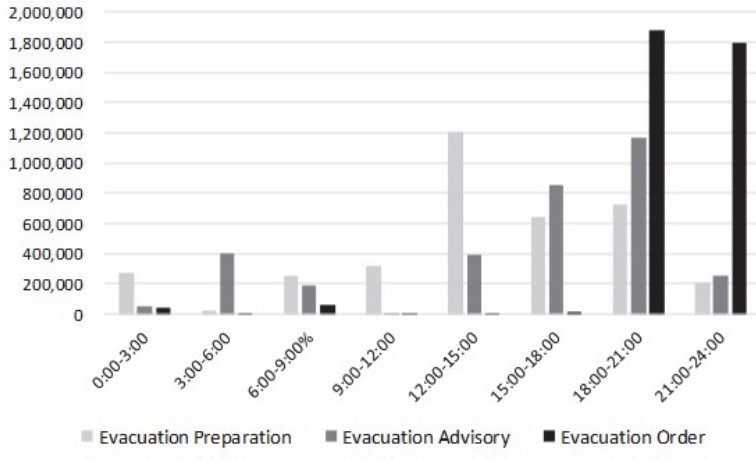

d) In total

Fig. 10 The accumulated number of residents targeted by the evacuation protocol over a three-hour time period.

Next, Table 2 presents the summary statistics, which includes the mean values, standard deviations, maximum values, and minimum values of the time interval between the evacuation protocol. The mean value of the time interval between the evacuation preparation and evacuation advisory was approximately $5.38 \mathrm{~h}$, but the shortest time interval was 18 min. The mean value between the evacuation advisory and evacuation order was $3.33 \mathrm{~h}$, but the shortest time interval was $20 \mathrm{~min}$. Finally, the mean value between the evacuation preparation and the evacuation order was $11.25 \mathrm{~h}$, but the shortest time interval was approximately $1.5 \mathrm{~h}$.

The mean time intervals were sufficient to respond to the heavy-rain threats, but the shortest time intervals were not sufficient for residents to take protective actions. In addition, as shown in Figure 9, many municipalities could not issue evacuation protocol in the expected order. These results suggest that the residents' plans to respond to heavy-rain threats should not only rely on evacuation protocol.

\section{(4) Relationships between the landslide meteoro- logical information and the evacuation proto- col}

As previously described, the guideline issued by the national government show the relationships between the heavy-rain warning (landslide) and the
Table 2 Time intervals of the evacuation protocol.

\begin{tabular}{|c|c|c|c|c|}
\hline & & Okayama Hiroshima & Ehime & In total \\
\hline \multirow{4}{*}{$\begin{array}{c}\text { Advisory } \\
\text { Preparation }\end{array}$} & M & 7h.55m. $\quad 4 \mathrm{~h} .28 \mathrm{~m}$. & $6 \mathrm{~h} .5 \mathrm{~m}$. & $5 \mathrm{~h} .23 \mathrm{~m}$ \\
\hline & $\mathrm{SD}$ & $5 \mathrm{~h} .29 \mathrm{~m}$. & $5 \mathrm{~h} .17 \mathrm{~m}$. & $5 \mathrm{~h} .28 \mathrm{~m}$. \\
\hline & Max & $29 \mathrm{~h} .10 \mathrm{~m} .25 \mathrm{~h} .48 \mathrm{~m}$ & $84 \mathrm{~h} .30 \mathrm{~m}$. & $84 \mathrm{~h} .30 \mathrm{~m}$. \\
\hline & Min & $50 \mathrm{~m}$. & $1 \mathrm{~h} .50 \mathrm{~m}$. & $18 \mathrm{~m}$. \\
\hline \multirow{4}{*}{$\begin{array}{c}\text { Order } \\
- \\
\text { Advisory }\end{array}$} & M & $2 \mathrm{~h} .58 \mathrm{~m}$ & $5 \mathrm{~h} .29 \mathrm{~m}$ & $3 \mathrm{~h} .19 \mathrm{~m}$. \\
\hline & SD & $2 \mathrm{~h} .13 \mathrm{~m}$ & $6 \mathrm{~h} .49 \mathrm{~m}$ & 3h.50m. \\
\hline & Max & m. $27 \mathrm{~h} .20 \mathrm{~m}$ & $23 \mathrm{~h} .28 \mathrm{~m}$. & $136 \mathrm{~h} .55 \mathrm{~m}$ \\
\hline & Min & $25 \mathrm{~m}$. & $20 \mathrm{~m}$. & $20 \mathrm{~m}$. \\
\hline \multirow{4}{*}{$\begin{array}{l}\text { Order } \\
\text { - }\end{array}$} & M & $9 \mathrm{~h} .25 \mathrm{~m} . \quad 11 \mathrm{~h} .28 \mathrm{~m}$. & $8 \mathrm{~h} .14 \mathrm{~m}$. & $11 \mathrm{~h} .15 \mathrm{~m}$. \\
\hline & $\mathrm{D}$ & $9 \mathrm{~h} .29 \mathrm{~m}$. & $7 \mathrm{~h} .59 \mathrm{~m}$. & $9 \mathrm{~h} .21 \mathrm{~m}$. \\
\hline & Max & 144h.55m. $27 \mathrm{~h} .50 \mathrm{~m}$. & $22 \mathrm{~h} .25 \mathrm{~m}$ & $144 \mathrm{~h} .55 \mathrm{~m}$ \\
\hline & Min & 3h. $59 \mathrm{~m} . \quad 1 \mathrm{~h} .35 \mathrm{~m}$. & $1 \mathrm{~h} .35 \mathrm{~m}$ & $1 \mathrm{~h} .35 \mathrm{~m}$. \\
\hline
\end{tabular}

Abbreviations:

$\mathrm{M}$, mean; SD, standard deviation;

Max, maximum; Min, minimum;

h., hour(s); m., minute(s)

evacuation preparation, the landslide alert information and the evacuation advisory, and the heavyrain emergency warning (landslide) and the evacuation order. In other words, if the municipalities followed the guideline, they should have considered an 
issuance of the related evacuation protocol. Following is a description of the relationship between the meteorological information and the corresponding evacuation protocol.

First, for the residents that were targeted by the heavy-rain warning (landslide) and the evacuation advisory, Figure 11 represents their proportions based on the temporal order. The proportion of the residents targeted by the evacuation preparation after the heavy-rain warning (landslide) was different between the prefectures, but the proportion of the residents targeted by the evacuation preparation after the heavy-rain warning (landslide) was almost $100 \%$ for all the prefectures. These results imply that the municipalities narrowed down the targets of the evacuation preparation from those for the heavy rain warning (landslide). This advantage of the evacuation protocol might help the targets recognize the landslide risk.

Second, for the residents that are targeted by the evacuation advisory and the landslide alert information, Figure 12 represents the proportions of the residents based on the temporal order. The proportion of the residents that were targeted by the evacuation advisory after the landslide alert information was approximately $40 \%-60 \%$, but the proportion of the residents targeted by the landslide alert information before the evacuation advisory was more than $90 \%$ in all the prefectures. It is also interpreted that the municipalities narrowed down the targets of the evacuation advisory in response to the landslide alert information.

Third, for the residents targeted by the heavy-rain emergency warning (landslide) and the evacuation order, Figure 13 represents the proportion of the residents with respect to the temporal order. The results are very similar to those of the previous two relationships. However, it should remind us that the guideline recommends that the heavy-rain emergency warning (landslide) is positioned not as an information source for the issuance of the evacuation order, but for reviewing the targets by the evacuation advisory and evacuation order. In this sense, it can be interpreted that many municipalities were moderate with respect to the issuances of the evacuation order, and the announcements of the heavy-rain emergency warnings (landslide) removed their hesitation to issue an evacuation order.

Table 3 presents the summary statistics, which includes the mean values, standard deviations, maximum values, and minimum values for the time intervals of the corresponding information.

First, the mean time interval between the heavyrain warning (landslide) to the evacuation preparation was approximately $17 \mathrm{~h}$. In other words, municipali-

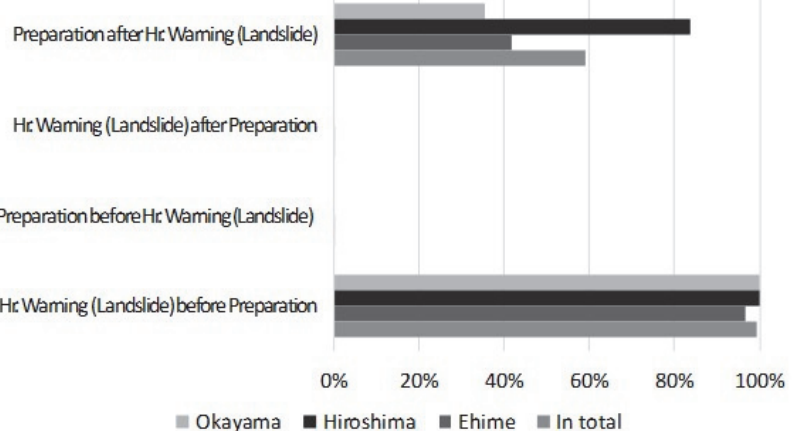

Fig. 11 Proportions of the residents targeted by the evacuation preparation and heavy-rain warning (landslide) based on the temporal and reverse temporal order.

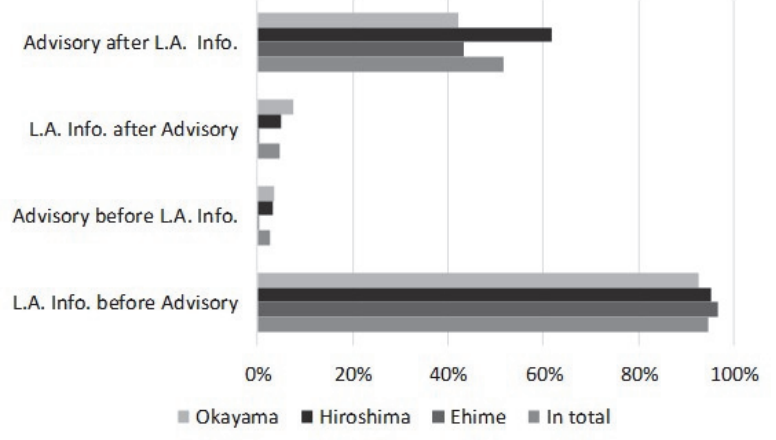

Fig. 12 Proportions of the residents targeted by the evacuation advisory and the landside alert information based on the temporal and reverse temporal order.

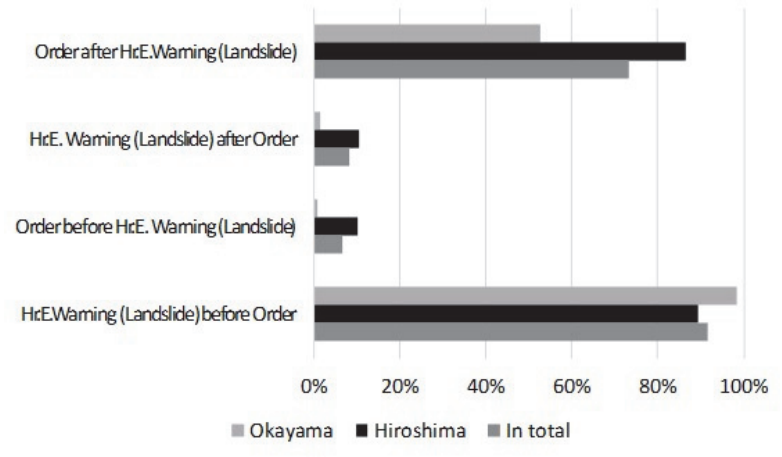

Fig. 13 Proportions of the residents targeted by the evacuation order and the heavy-rain emergency warning (landslide) based on the temporal and reverse temporal order.

ties were not likely to respond to the heavy-rain warning (landslide) immediately. It seems that only the municipalities that issued the evacuation preparation regarded the heavy-rain warning (landslide) as a necessary condition to issue the evacuation preparation. In addition, a few municipalities, particularly in Okayama and Ehime, did not issue the evacuation preparation. Thus, it is concluded that the heavy-rain warning (landslide) did not fully function as an information source for issuing the evacuation preparation.

Second, as for the time interval from the landslide 
Table 3 Time interval between the landslide-related meteorological information and the evacuation protocol.

\begin{tabular}{|c|c|c|c|c|c|}
\hline & & Okayama & Hiroshima & Ehime & In total \\
\hline \multirow{4}{*}{$\begin{array}{l}\text { Hr. Warning } \\
\text { (landslide) } \\
\text { - } \\
\text { Preparation }\end{array}$} & M & $16 \mathrm{~h} .31 \mathrm{~m}$. & $17 \mathrm{~h} .32 \mathrm{~m}$. & $12 \mathrm{~h} .59 \mathrm{~m}$. & $17 \mathrm{~h} .15 \mathrm{~m}$. \\
\hline & SD & $6 \mathrm{~h} .42 \mathrm{~m}$ & $11 \mathrm{~h} .29 \mathrm{~m}$. & $9 \mathrm{~h} .16 \mathrm{~m}$. & $10 \mathrm{~h} .44 \mathrm{~m}$. \\
\hline & Max & $27 \mathrm{~h} .30 \mathrm{~m}$ & $31 \mathrm{~h} .10 \mathrm{~m}$. & $29 \mathrm{~h} .24 \mathrm{~m}$. & $31 \mathrm{~h} .10 \mathrm{~m}$. \\
\hline & Min & $7 \mathrm{~m}$. & $2 \mathrm{~h} .5 \mathrm{~m}$. & 1h. $14 \mathrm{~m}$. & $7 \mathrm{~m}$. \\
\hline \multirow{4}{*}{$\begin{array}{l}\text { Landslide } \\
\text { Alert Info. } \\
\text { - } \\
\text { Advisory }\end{array}$} & M & $16 \mathrm{~h} .4 \mathrm{~m}$. & $58 \mathrm{~m}$ & $16 \mathrm{~h} .30 \mathrm{~m}$. & $5 \mathrm{~h} .59 \mathrm{~m}$. \\
\hline & $\mathrm{SD}$ & $9 \mathrm{~h} .5 \mathrm{~m}$. & $51 \mathrm{~m}$ & 10h.16m. & $8 \mathrm{~h} .58 \mathrm{~m}$. \\
\hline & Max & $26 \mathrm{~h} .25 \mathrm{~m}$. & 4h.0m. & $29 \mathrm{~h} .5 \mathrm{~m}$. & $29 \mathrm{~h} .5 \mathrm{~m}$. \\
\hline & Min & $20 \mathrm{~m}$. & $5 \mathrm{~m}$. & $25 \mathrm{~m}$ & $5 \mathrm{~m}$. \\
\hline \multirow{4}{*}{$\begin{array}{c}\text { Hr. E. } \\
\text { Warning } \\
\text { (landslide) } \\
\text { — } \\
\text { Order }\end{array}$} & M & 1h. $39 \mathrm{~m}$. & $16 \mathrm{~m}$. & - & $23 \mathrm{~m}$ \\
\hline & SD & 1h. $9 \mathrm{~m}$. & $25 \mathrm{~m}$. & - & $39 \mathrm{~m}$. \\
\hline & Max & $23 \mathrm{~h} .5 \mathrm{~m}$. & $9 \mathrm{~h} .40 \mathrm{~m}$. & - & $23 \mathrm{~h} .5 \mathrm{~m}$. \\
\hline & Min & $20 \mathrm{~m}$. & $1 \mathrm{~m}$. & - & $1 \mathrm{~m}$. \\
\hline
\end{tabular}

Abbreviations:

Hr., Heavy-rain; E., Emergency; Info., Information;

M, mean; SD, standard deviation;

Max, maximum; Min, minimum;

h., hour(s); m., minute(s)

alert information to the evacuation advisory, the shortest time interval in each prefecture was less than $30 \mathrm{~min}$. This result implies that some municipalities quickly issued the evacuation advisory in response to the landslide alert information. However, the longest time interval was approximately $4 \mathrm{~h}$ in Hiroshima and more than $1 \mathrm{~d}$ in Okayama and Ehime. From this, it is concluded that some of the municipalities made use of the landslide alert information as expected, while others did not.

Finally, in regard to the time interval from the heavy-rain emergency warning (landslide) to the evacuation order, almost all of the municipalities in Hiroshima promptly responded to the announcements, but the municipalities in Okayama responded to the announcements with a time lag of $1 \mathrm{~h}$ or more on average, in comparison to $25 \mathrm{~min}$ for Hiroshima. It is desirable that the municipalities respond to the heavy rain emergency warning as soon as possible. As a result, it is concluded that the municipalities promptly responded to the heavy-rain emergency warning (landslide), although it would have been better for them to issue the evacuation order in advance.

\section{(5) Further Discussion}

This study clarified the characteristics of the meteorological information related to heavy rainfall and the evacuation protocol during the heavy-rain event of July 2018. The results imply that the municipalities differed in the implementation of the evacuation protocol and the utilization of the metrological information. The meteorological information provides the primary information regarding hazards, and the evacuation protocol corresponds to the secondary information regarding the meteorological information. Therefore, the municipalities should respond to the meteorological information as promptly as possible. On the other hand, the municipalities can narrow down the targets of the evacuation protocol at their discretion, although it takes time. This may help residents identify the risk of a heavy rainfall as their own risk. It is important to clarify the factors affecting the time intervals, and to help the residents recognize the existing time intervals. In addition, residents need a plan to respond to the heavy-rain threats, in which they must rely on multiple information sources, including meteorological information and evacuation protocol. This is a topic for future research.

\section{CONCLUSION}

This paper presents the characteristics of the meteorological information related to heavy rainfall and the evacuation protocol during the heavy rain event of July 2018. This study showed that there were many municipalities that were unable to issue an evacuation preparation, and the proportion of residents who received the evacuation protocol in the order of the evacuation preparation, the advisory, and the order was less than $50 \%$ of the residents targeted by the evacuation order. In addition, this study showed that there were time intervals between the landslide meteorological information and the related evacuation protocol. This implies that the use of the meteorological information could be inconsistent between the municipalities.

This paper describes the characteristics of the evacuation protocol issued by the municipalities. More detailed characteristics can be obtained by considering a variety of factors that may affect their decisions on issuances, such as the population size, the crisis management system, past experiences on the issuance, or geographical conditions. In addition, this study only deals with heavy-rain (emergency) warnings and landslide alert information as meteorological information, but other information, such as the flood forecast for designated rivers or a flood advisory/warning, are not included. Inclusion of this information in the analysis can have more implications, especially for flood-prone areas.

Finally, with this event as a turning point, the related institutions were revised ${ }^{11)}$. In other words, it was institutionalized, which alert levels (1-5) were associated with the meteorological information and 
the evacuation protocol. It is expected that the residents can easily understand their situations regarding the incoming hazardous threats. This association may provide a robust environment where the residents can easily respond to the disaster-related meteorological information and the evacuation protocol. On the other hand, based on the analysis that was previously mentioned, the time intervals between the meteorological information and the evacuation information must exist. Consequently, this institutional arrangement may provide a complex environment where the alert level of the meteorological information does not coincide with the evacuation protocol. The municipalities and residents are required to make a plan to respond to heavy-rain threats based on this arrangement. This should be further investigated in the near future.

ACKNOWLEDGMENT: The authors would like to thank the municipalities that provided the data along with the telephone support.

\section{REFERENCES}

1) JMA: Landslide Alert Information and Real-time Landslide Risk Map. https://www.jma.go.jp/jma/kishou/know/bosai/ doshakeikai.html (only in Japanese, accessed 20 April 2019)

2) JMA: Emergency Warning System - A New Service to Protect Life -, August 2018. http://www.jma.go.jp/jma/en/ Emergency_Warning/Leaflet (Emergency_Warning_Syste m).pdf (accessed 25 April 2019)

3) JMA: Emergency Warning System. https://www.jma.go.jp/ jma/en/Emergency_Warning/ew_index.html (accessed 30 August 2020)

4) JMA: Criteria for Issuance of Emergency Warnings - Rela tionships between criteria and indices. https://www.jma. go.jp/jma/en/Emergency_Warning/Relationships_between _criteria_and_indices.pdf (accessed 30 August 2020)

5) The Cabinet Office: The Guideline about Evacuation Advisory and others (1) (Evacuation and Information Transfer), August 2017. http://www.bousai.go.jp/oukyu/hinankankok u/h28_hinankankoku_guideline/pdf/hinankankokugaidorai n_01.pdf (in Japanese, accessed 25 April 2019)

6) The Cabinet Office: The Guideline about Evacuation Advisory and others (2) (Issuance Standard and Disaster Prevention System), January 2017. http://www.bousai.go.jp/oukyu /hinankankoku/h28 hinankankoku guideline/pdf/hinankan kokugaidorain_02.pdf (in Japanese, accessed 25 April 2019)

7) Kodama, M., Honma, M., Katada, T. and Wakatabe, J.: Issues about use of disaster information for response of disaster mitigation at a heavy rainfall by municipalities, Journal of Disaster Information Studies, No.7, pp.75-83, 2009. (in Japanese)

8) JMD: The Heavy-rain Event of July 2018. https://www. data.jma.go.jp/obd/stats/data/bosai/report/2018/2018071/ 20180713.html (in Japanese, accessed 26 April 2019)

9) e-Stat (Portal Site of Official Statistics of Japan): 2015 Population Census - Small Area Units. https://www.estat.go.jp/en (accessed 26 April 2019)

10) National Land Numerical Information Download Service. http://nlftp.mlit.go.jp/ksj/ (accessed 26 April 2019)

11) The Cabinet Office: Key Evacuation Information Explanations, May 2020. http://www.bousai.go.jp/oukyu/hinankank oku/h30_hinankankoku_guideline/pdf/campaign_en. pdf (accessed 17 August 2020)

(Received August 31, 2020)

(Accepted October 29, 2020) 